\title{
Finding the middle ground-adopting the Doctor of Nursing Practice for nurse practitioner education as a post-Master's program while leaving Master's level education intact
}

\author{
Pamela Aselton, Kimberly Joerg, Sandra G. Affenito \\ Department of Nursing, School of Health and Natural Sciences, University of Saint J oseph, CT, USA \\ Correspondence: Pamela Aselton. Address: Department of Nursing, School of Health and Natural Sciences, University of \\ Saint Joseph, 1678 Asylum Avenue, West Hartford, CT 06117, USA. Email: paselton@usj.edu
}

Received: January 9, 2013

Accepted: February 21, 2013

Online Published: February 26, 2013

DOI : 10.5430/cns.v1n1p51

URL: http://dx.doi.org/10.5430/cns.v1n1p51

\begin{abstract}
With the full implementation of the Patient Protection and Affordable Care Act, educating a sufficient number of NPs for the workforce is more important than ever. Given the recommendations relating to the elevation of Nurse Practitioner (NP) education to the doctoral level, many nursing programs with Master's level NP programs initiated planning for BSN to DNP programs and eliminated their Master's programs, however many schools were unable to make the change. It has been the department's experience that most of the working nurses who apply to our NP program prefer to start their training at the Master's level with an eventual goal to resume their doctoral studies at a later date. While this incremental model may delay initial goals of transferring all NP education to the doctoral level, it appears to be a model that works for working nurses and may be how many nurses prefer to be educated.
\end{abstract}

\section{Key words}

Nurse practitioner education, Doctor of Nursing Practice, Nursing education

\section{I ntroduction}

With an increase in the aging population in the United States and the current implementation of health care reform, there is a focus on patient-centered primary care and a need for more primary care providers ${ }^{[1,2]}$. Nurse practitioners (NPs) and Clinical Nurse Specialists in a variety of disciplines have helped to address this need by contributing significantly to the primary care workforce for the past five decades ${ }^{[3]}$. Traditionally these NPs and Clinical Nurse Specialists have been educated at the Master's level. When the American Association of Colleges of Nursing (AACN) announced their plan of transitioning the education of all NPs to the doctoral level, many nursing schools scrambled to change their graduate programs from a Master's program to a BSN to DNP degree model ${ }^{[4]}$. Many large schools have successfully made this transition; however several small programs have struggled to start doctoral programs for NP education ${ }^{[5]}$. Although nurses with a variety of clinical specialties, including clinical nurse specialists, nurse anesthetists, nurse midwives and NPs are eligible for the Doctor of Nursing (DNP) degree, this article will specifically address the education of NPs in DNP 
programs and the experience of a nursing department's decision to keep Master's degree education while adding a post-Master's DNP.

\section{The evolving role of the DNP}

The concept of the DNP degree was intended to elevate the education and the number of faculty-supervised clinical hours that NPs needed, in order to reflect the increasing responsibilities in the workplace. The thinking was that DNP practitioners would be prepared to assume leadership roles and have an advanced understanding of quality improvement, health care systems, and information technology in the healthcare workplace. These areas, as outlined in The Essential Document of Doctoral Education for Advanced Nursing Practice, are necessary components of the DNP role ${ }^{[4]}$. Although the original idea of the DNP degree was to be a practice-oriented degree that focused on educating clinicians to implement and evaluate evidence-based care, DNPs are not only working in all areas of clinical practice, but are vital members of institutions of higher education in preparing future nurses for careers in a variety of healthcare setting $\mathrm{s}^{[6]}$.

The roles of the DNP graduate continue to expand in a variety of employment settings. A recent survey of DNP students in ten American Universities found that most students cited eligibility to work as nursing faculty along with excellence in clinical practice as a major reason for choosing the DNP ${ }^{[6]}$. DNP students also expressed a desire to stay focused on clinical practice and increase their technological skills to meet the increasingly complex needs of patients ${ }^{[7]}$. Improved patient care outcomes rely on NPs understanding the increasingly complex healthcare system and their ability to synthesize the tremendous amount of health-related information that is available to the patient. As examples, occupational health nurses who pursue DNPs have developed interventions in the workplace to support health, and hospital nursing staff have had lead roles in obtaining magnet certification for their institutions. These are all part of the innovations that the DNP degree is hoping to achieve ${ }^{[8]}$.

The advancement to the terminal degree in nursing practice is similar to the developments in other allied health fields such as physical therapy and pharmacy, which are progressing to the PharmD and DPT credentials, respectively ${ }^{[1]}$. Numerous nursing programs have kept NP education at the Master's level, and some that had converted fully to a post-BSN-DNP model have reopened Master's level tracks for NP education. The majority of programs in the United States offer only the MSN to DNP option (56\%), but a growing number (43\%) offer both a BSN to DNP and an MSN to DNP option ${ }^{[9]}$. To date, data are being systematically evaluated on 137 DNP programs across the United States to provide a benchmark for the admission and retention of potential nursing students who will be successful DNP candidates ${ }^{[9,10]}$.

\section{An incremental approach}

A small Master's degree program of 30-40 students in New England for Family and Psychiatric NPs initiated an action plan in 2008 to transition all NP training to the doctoral level after careful consideration of the recommendations to elevate the level of education for Nurse Practitioners to the doctoral level by 2015. As part of this plan to convert to a BSN-DNP model, the department was looking at the necessity of closing admissions to the Master's level tracks by 2011, in order to have students complete their coursework, in preparation for certification exams.

During this period of time, many other programs in the country were not able to transition their programs for a variety of reasons, including the shortage of doctorally-prepared nurses to fill the roles of nursing faculty ${ }^{[11]}$. The inability to alter these nursing education programs resulted in the protest of this decision due to the potential inability of numerous existing Master's programs to educate NPs for the workforce at the doctoral level ${ }^{[2]}$. An example of the effect of this decision is provided by the California State University system which housed many Master's level Nurse Practitioner preparation programs, but was unable to offer doctoral programs ${ }^{[12]}$. These Master's level NP education programs examined the possibility of closing programs by 2015, if the mandate for doctoral level preparation by 2015 was required for certification exam eligibility. Currently, this legislation has been updated to allow for the DNP degree on three campuses 
of California State University system ${ }^{[12]}$. The California law is cited as an example of removing regulatory barriers and preparing more nurses at the doctoral level for high demand clinical and faculty positions.

\subsection{Solutions evolve over time}

After an initial plan to transition the NP education from a Master's preparation to a BSN to DNP model in 2010 was presented, the University was advised during the site visit from the State Board of Higher Education to consider changing the application to a post-Master's only DNP model. This would maintain the actively growing Master's programs for NP education. The reviewer had based this decision on the experience of other programs in the state that had made the transition earlier. This solution allowed the Department of Nursing to rework the proposal and focus only on the core DNP courses that would be new to the program. These courses provided an emphasis on evidence-based practice, informatics, systems thinking, and fiscal analysis, as well as clinical practice issues incorporated into dissertation research ${ }^{[13]}$.

This redesign has resulted in a viable solution for the University and has kept enrollment at healthy levels in the graduate program. The current Master's programs now have over 120 FNP and Psychiatric NP students. Udlis and Mancuso ${ }^{\text {[9] }}$ postulate that many institutions have been motivated to keep their Master's programs intact because of the increased likelihood of reducing enrollment in already well-established programs. However, enrollment data have shown that the attrition rate for programs where NP grads are allowed to "step out” at the Master's level tends to be high.

It has been the department's experience that most of the working nurses who apply to the DNP program and want to become NPs prefer to start their education at the Master's level with an eventual goal to resume doctoral studies at a later date. Once the NPs are in clinical practice, they discover a number of emerging clinical issues which need to be addressed; hence their desire to begin doctoral work and a clinical dissertation. If nursing regulatory bodies decide that NP certification exams will only be offered to doctorally-prepared NP students in the future, the Department of Nursing is prepared as the curriculum has been approved already by the University's graduate curriculum committee for a full BSN-DNP program conversion.

\subsection{Allowing for nurse practitioner certification in post-Master's DNP}

For those students who did not have Nurse Practitioner certification in their first Master's degree, the courses necessary for certification may be added to the DNP plan of study including 1000 clinical hours of practice. Students with prior certification as NPs or Clinical Nurse Specialists may transfer in up to 750 hours of their previous faculty supervised clinical hours, but must do an additional 500 clinical hours in their new specialty in order to sit for the certification exam. Instead of completing a second Master's degree with a minimum of 30 credits, these students are able to progress to the doctoral level, as well as obtain the desired NP certification. The completion of the DNP allows nurses more opportunities in teaching, clinical practice, and research ${ }^{[1]}$. Many graduates transition into careers in higher education or affiliate with clinical practices. The DNP graduates are educated to assume leadership positions with an increased appreciation of the ethical, policy and financial aspects of the healthcare system ${ }^{[14]}$.

For those students who have already obtained their NP certification in their Master's education, this post-Master's plan of study allows the student to use evidence-based research to effect change in a given clinical area or problem of concern in practice. Compared with the traditional Ph.D. in nursing which focuses on research techniques and creating new research in nursing practice; the DNP emphasizes advances in clinical practice relative to the emerging new paradigm of health care as documented in the agenda of the health care reform. The DNP has truly become the new doctoral degree in nursing and prepares nurses for more responsibility in delivering healthcare ${ }^{[15]}$.

\subsection{Reluctance by some adult learners to enter a DNP program}

Once the post-Master's program was established, students seeking NP certification with a previous Masters in Nursing were offered to complete their NP education in the DNP program. However, many students holding a Master's degree in nursing wanted to complete their clinical education as a second Master's degree rather that a DNP degree. Although they 
are encouraged to pursue the DNP degree along with their certification rather than earning a second Master's degree, many students are eager to enter the workforce as an NP. Financial concerns regarding the cost of completing a DNP degree compared with a second Master's degree are also a motivation to complete NP education within a Master's degree program, even if the student has earned already a Master’s degree in Nursing.

\subsection{The importance of previous nursing experience}

Nursing faculty need to consider the developmental stages of practice acquisition in evaluating BSN to DNP models for NP education. The evaluation of the DNP degree's ability to provide leadership skills as well as practice skills is an ongoing process in universities that have developed this model of NP preparation ${ }^{[7]}$. It has been our experience that requiring some clinical experience in nursing prior to entering the Master's program gives NP students a much needed foundation on which to advance studies for future clinical roles. Preceptors have noted their preference for experienced nurses for clinical internship placements for NP students. Most current students work in nursing positions while completing the program part-time, allowing for additional clinical experience and knowledge.

\section{Conclusions}

Moving the nursing profession forward with the DNP role in all areas of practice will continue to evolve. While the concept of elevating the level of education required for Nurse Practitioners and increasing their faculty supervised clinical hours is a noble goal, the more incremental approach of keeping the Master's programs intact for NP education while adding DNP coursework in a post-Masters DNP program has been a more workable solution for some institutions. The plan to transition all nursing programs to include a BSN to DNP model will evolve as the market and state regulatory agencies dictate. Although keeping Master's level education options open for Bachelor's-prepared nurses may slow the transition to a national consensus to require the DNP for NP certification, it is a very feasible resolution to maintain an adequate number of health care providers being educated to meet the demand for primary care and mental health providers. It also appears to be preferable for nursing students to have a more incremental approach to higher education as many are working nurses.

Looking to the future, nursing is favorably positioned in a continually evolving health care system that strives to improve the quality of care provided to patients. Given the shortage of doctorally-prepared nurses in the country, increasing the number of DNP programs in the United States is essential. The faculty shortage along with the need for more mental health and primary care providers with health care reform make Primary Care FNP and Psychiatric NP graduates highly marketable whether they are prepared at the Master's or Doctoral level.

\section{References}

[1] Nair M, Webster P. Education for health professionals in the emerging market economies: A literature review. Med Educ. 2008 Sept; 44(9): 856-863. PMid:20716095 http://dx.doi.org/10.1111/j.1365-2923.2010.03747.x

[2] Dracup K, Cronenwett L, Meleis A, Benner P. Reflections on the doctorate of nursing practice. Nurs Outlook. 2005 ; 53: 177-182. PMid:16115509 http://dx.doi.org/10.1016/j.outlook.2005.06.003

[3] Poghosyan L, Lucero R, Rauch L. Berkowitx B. Nurse practitioner workforce: A substantial supply of primary care providers. Nurs Econ. 2012; 30 (5):268-274. PMid:23198609

[4] American Association of Colleges of Nurses. The Essentials of Doctoral Education for Advanced Nursing Practice [Internet]. 2006[cited 2012 Dec 5]. Available from http://www.aacn.nche.edu/publications/position/DNPEssentials.pdf.

[5] Chase SK. Pruit RH. The practice doctorate: innovation or disruption? J Nurs Educ. 2006; 45:155-161. PMid:16722497

[6] Loomis J,Willard B, Cohen J. Difficult Professional Choices: Deciding Between the Ph.D. and the DNP in Nursing. Online J Issues Nurs. 2007 Jan 7; 12(1).

[7] Kaplan l. Brown MA. Doctor of Nursing practice- Program Evaluation and beyond: Capturing the profession’s Transition to the DNP. Nurs Educ Perspect.2009 Nov-Dec; 30 (6): 362-366. PMid:19999937

[8] Terry AJ. Clinical research for the Doctor of Nursing Practice. Sudbury, MA: Jones \& Bartlett Learning; 2012 May 27. 
[9] Udlis KA, Mancuso JM. Doctor of nursing practice programs across the United States: A Benchmark of information: Part I; Program Characteristics. J Prof Nurs. 2012 Sept-Oct; 28 (5): 265-273. PMid:23006648 http://dx.doi.org/10.1016/j.profnurs.2012.01.003

[10] Mancuso JM. Udlis KA. Doctor of nursing practice programs across the United States: A benchmark of information: Part II: Admission criteria. J Prof Nurs. 2012 Sept-Oct; 28(5): 274-283. PMid:23006649 http://dx.doi.org/10.1016/j.profnurs.2012.01.002

[11] Institute of Medicine Report. Health Professions Education: a Bridge to Quality. Washington, DC; National Academies Press; 2003 April 18.

[12] American Association of Colleges of Nursing. New Law Allows California State Nursing Schools to Offer the DNP. Press release [Internet]. 2010[cited 2012 Dec 28]. Available from: http://www.aacn.nche.edu/news/articles/2010/dnp-bill

[13] American Association of Colleges of Nurses. AACN Position Statement on the Practice Doctorate in Nursing [Internet]. 2004[cited 2012 Nov 21]. Available from http://www.aacn.nche.edu/dnp/talking-points.pdf.

[14] Jacobson PD, Gostin LO. Restoring health to health reform. JAMA, 2010; 304(1): 85-86. PMid:20606153 http://dx.doi.org/10.1001/jama.2010.917

[15] DeNisco S, Barker AM. Advance practice nursing- evolving roles for the transformation of the profession. Burlington, MA: Jones \& Bartlett Learning; 2013. 